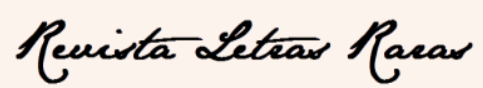

ISSN: 2317-2347 - v. 7, Edição Especial (2018).

\title{
Jack and Harry: No turning back, de Tony Mckenna e Mervyn Davis e a adaptação do yarn para o romance na literatura juvenil australiana / Jack and Harry: No turning back, by Tony Mckenna and Mervyn Davis and the adaptation of the yarn into the novel in the teen/young adult literature of Australia
}

Déborah Scheidt*

\section{RESUMO}

O gênero textual yarn se refere a uma modalidade de literatura oral popular bastante difundida na Austrália e que apresenta algumas semelhanças com o "causo" no Brasil e o tall tale nos Estados Unidos. Este artigo procura examinar a adaptação do yarn para o público juvenil contemporâneo no romance Jack and Harry: No turning back, de autoria de Tony McKenna e Mervyn Davis (2005). Serão analisadas as versões impressa e em audiolivro do romance, avaliando-se fatores que aproximam (mas que também por vezes distanciam) o texto do gênero yarn, tais como o caráter performático da narração oral feita pelo ator australiano David Tredinnick, o ritmo da narrativa e a influência da chamada "tradição rural australiana" (Australian bush tradition), já que a trama aborda temas tais como o igualitarismo e o mateship, o tradicional preceito da lealdade incondicional entre viajantes do interior australiano. Também serão considerados aspectos da história de aventura como fórmula literária.

PALAVRAS-CHAVE: Jack and Harry: No turning back; Tony McKenna e Mervyn Davis; yarn; literatura popular; literatura juvenil, Austrália.

\section{ABSTRACT}

The yarn, as a text genre, refers to a mode of oral folk literature very popular and widespread in Australia, which presents some similarities to the "causo" in Brazil and the tall tale in the U.S. This article attempts to examine the adaptation of the yarn to suit a contemporary teen and young adult public in the novel Jack and Harry: No turning back, by Tony McKenna e Mervyn Davis (2005). The audiobook and printed versions of the novel will be the focus of analysis and will provide material for the evaluation of the factors that approximate (and at times distance) the novel from the yarn, such as the performance of the voice artist, the Australian actor David Tredinnick, the rhythm of the narrative, as well as the influence of the so-called "Australian tradition/legend", which brings to the plot themes such as egalitarianism and mateship, the traditional institution of unconditional loyalty between travellers in the Australian outback. Some aspects of the adventure story as a literary formula will also be considered. KEYWORDS: Jack and Harry: No turning back; Tony McKenna and Mervyn Davis; yarn; folk literature; teen literature, Australia.

\section{Introdução}

Em um sábado de novembro, 1950, na ensolarada Perth, costa oeste da Austrália, os amigos Jack Ferguson e Harry Turner (com 15 e 14 anos de idade)

\footnotetext{
* Doutorado em Letras (Estudos Literários) pela UFPR, Mestrado em Letras (Literaturas de Língua Inglesa) pela UFPR e realizou Estágio Pós-Doutoral na Univsersity of Sydney, Austrália. Professora do Departamento de Estudos da Linguagem da Universidade Estadual de Ponta Grossa - UEPG - PR, Brasil, deborahscheidt@yahoo.com.br.
} 


\section{Reuista Leteas Racas}

ISSN: 2317-2347 - v. 7, Edição Especial (2018).

divertem-se pedalando a nova bicicleta de corrida emprestada por seu colega de escola, Billy Munse: "Jack descia a trilha em direção ao rio enquanto Harry, incapaz de se conter, corria ao lado do amigo, encorajando-o aos berros: 'Mais rápido, Jack! Pode ir, ela dá conta!"” (MCKENNA; DAVIS, 2005a, p. 13) ${ }^{1}$ A certa altura, no entanto, percebem uma mudança no comportamento de Billy. O rapaz, que momentos antes vangloriava-se da bicicleta e insistia para que os colegas a testassem, agora grita e gesticula desesperadamente, chamando-os de volta. Ocorre que o pai de Billy, que havia proibido o filho de ceder o presente de aniversário para os "pés-rapados da vizinhança"2 (MCKENNA; DAVIS, 2005a, p. 9), também observa a cena, furioso. Para evitar o castigo iminente, Billy acusa Jack e Harry de terem roubado a bicicleta.

Esse é o elemento catalisador de vários episódios aventurescos pelo interior da Austrália que comporão o romance juvenil Jack and Harry: No turning back, de Tony McKenna e Mervyn Davis (2005), parte de uma duologia que se complementa com Jack and Harry II: Beyond tomorrow (2015). Os eventos da trama se sucedem rapidamente após o caso ser levado à polícia e aparecerem "testemunhas" - na verdade amigos de Mr. Munse que se propõem a prestar falsos depoimentos contra Jack e Harry. Tomados pelo pavor de serem presos injustamente, os meninos orquestram um plano de fuga "sem retorno" - daí o no turning back do subtítulo. Seu objetivo é chegar a Coober Pedy, cidadezinha do outback australiano conhecida por ser a maior produtora de opalas no mundo. Além da possibilidade de fazer fortuna na mineração, Jack e Harry são atraídos pela reputação um tanto duvidosa do lugar. Dizem os boatos que "[h]á uma regra básica lá, uma lei não escrita, que é levada muito a sério: ninguém se mete nos negócios alheios. Ninguém faz perguntas e ninguém fala de seu passado ou de onde é"3 (MCKENNA; DAVIS, 2005a, p. 22).

A partir daí a trama acompanha os seis meses de errância dos jovens pelo interior australiano, percorrendo centenas de quilômetros entre três estados: Western Australia, Northern Territory e South Australia. Lançada em 2005, a versão em áudio do romance, narrada por David Tredinnick e apresentada em capítulos por uma das

\footnotetext{
1 "Jack rode off along the flat beside the river and Harry, unable to restrain himself, ran after him, shouting encouragement. 'Go faster, Jack! Give it to her, she can take it!'”' Neste trabalho as traduções de todos os trechos de obras originalmente escritas em inglês para o português são de minha autoria. 2 "local riff raff"

3 "They have a pretty tight unwritten law of their own up there and everyone keeps to themselves. They ask no questions and give no information about where they're from or about their past."
} 


\section{Revista Leteas Racar}

ISSN: 2317-2347 - v. 7, Edição Especial (2018).

estações de rádio pública mantidas pela ABC (Australian Broadcasting Corporation), precedeu sua edição impressa. Ao acompanharem o desenvolvimento dos heróis juvenis desde a perda da inocência até a superação das inseguranças da adolescência, os 39 capítulos formam um bildungsroman. Significativamente, quanto à temática e à forma, o romance e, em particular, a sua gravação em áudio retomam a modalidade literária popular conhecida no mundo anglófono - e especialmente na Austrália - como yarn.

\section{0 gênero textual yarn}

Yarn pode ser traduzido literalmente como "fio". Em seu sentido metafórico, no entanto, o termo designa uma categoria de narrativa popular predominantemente oral. Paul Gilge (2016, p. 106-107) localiza o surgimento da metáfora spin a yarn ("fiar", "produzir fio na roda de fiar") no mundo da navegação marítima britânica, não muito tempo anteriormente à colonização da Austrália (talvez final do século XVIII), a julgar pelas primeiras manifestações escritas do termo. A origem da expressão provavelmente remete à feitura de um tipo de corda náutica de múltiplas utilidades conhecida como spun-yarn. A atividade de torcer fibras para produzir essas cordas era normalmente realizada por três pessoas e presume-se que, para aliviar o tédio das longas e repetitivas horas destinadas ao trabalho, os marinheiros contavam histórias.

Essa metáfora, assim como tantas outras, é repleta de sabedoria popular, já que, como na atividade artesanal da fiação têxtil, o autor/narrador do yarn, nas palavras de Jim Haynes (2013, p. xvii), "pega alguns fios de uma história e os transforma em algo substancial ou significativo."4 A expressão parece ter encontrado terreno especialmente fértil nos assentamentos penais britânicos na Austrália, pois uma de suas primeiras definições impressas ocorre no glossário de jargões que acompanhava a autobiografia publicada em 1819 pelo inglês James Hardy Vaux, sentenciado por três vezes à prisão em New South Wales. Vaux define spinning a yarn como um passatempo favorito em agrupamentos de indivíduos delinquentes ou marginais, os quais

expõem uns para os outros suas várias aventuras, proezas e fugas. Essa atividade é extremamente comum e gratificante entre pessoas confinadas ou exiladas, pois anima os momentos de tédio e

\footnotetext{
4 "takes some threads of a story and makes something substantial or meaningful from them."
} 


\section{Remita Litaras Rear}

ISSN: 2317-2347 - v. 7, Edição Especial (2018).

provavelmente cria uma esperança secreta de que algum dia possam desfrutar novamente de prazeres passados ${ }^{5}$ (VAUX, 1819, p. 226)

Se ao desembarcar na Austrália a metáfora encontrou uma primeira acolhida no submundo do crime, ela rapidamente difundiu-se para outras comunidades discursivas, especialmente as rurais, localizadas nas áreas conhecidas como the bush ou outback, ${ }^{6}$ dando origem, assim, ao famoso bush yarn. Com isso também se ampliaram a diversidade de temas e o tom das narrativas. Os acontecimentos de um yarn podem ir do prosaico ao abertamente impossível, passando pelo espirituoso, inusitado, cômico e bizarro. Gwenda Davey e Graham Seal (2003, p. 276) observam que, mesmo quando aparentemente leves, os yarns frequentemente reservam uma "aguilhoada" ao final, ${ }^{7}$ ou procuram mostrar algo sobre os indivíduos ou eventos apresentados.

Ao lado de substantivos tais como bush, outback e mate, yarn pertence hoje à categoria de expressões da língua inglesa padrão que assumiram um espaço de destaque nas variantes australianas do inglês. Em termos estatísticos, yarn - que com o passar do tempo também passou a significar "bate papo" e "mentira", assim como os verbos "bater papo" e "mentir" - tem uma alta recorrência no léxico australiano. Assim como outros enunciados que denotam fenômenos culturais geograficamente delimitados, fica difícil estabelecer equivalentes exatos para yarn (em sentido metafórico) em outras línguas. Duas possibilidades de tradução aproximada são "causo" em português e tall tale em inglês norte-americano. Os estudos existentes sobre esses tipos de narrativa popular podem nos ajudar a analisar o yarn, bem como sua transposição para o romance contemporâneo.

\section{A transposição do yarn para o romance infanto-juvenil australiano}

Assim como outros gêneros textuais que dependem da oralidade, o yarn, o causo e o tall tale têm uma faceta performática, já que estão relacionados à habilidade técnica e à capacidade do(a) contador(a) de cativar seu público. De fato, a transposição eficiente

\footnotetext{
5 "relate their various adventures, exploits, and escapes to each other. This is most common and gratifying, among persons in confinement or exile, to enliven a dull hour, and probably excite a secret hope of one day enjoying a repetition of their former pleasures."

${ }^{6}$ The bush designa as áreas interiores mais próximas da costa enquanto que the outback configura a área mais central onde se encontram os desertos. Como não existe uma fronteira oficial entre the bush e the outback, essas denominações frequentemente se confundem e se sobrepõem. Ver: SCHEIDT, D. 2010.

7 "a sting in the tail"
} 


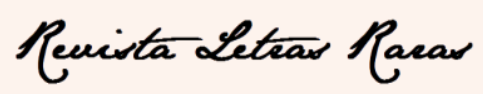

ISSN: 2317-2347 - v. 7, Edição Especial (2018).

desses gêneros para a linguagem escrita depende da manutenção de certas características do discurso oral. Nesse quesito, McKenna e Davis (2005) optam pela objetividade, a ação descomplicada e a informalidade da narrativa, com muitos australianismos (por exemplo, a prática de utilizar diminutivos para certas palavras: barbie para barbecue [churrasco] e coldie para cold beer [geladinha]) e até mesmo palavrões (os quais frequentemente provocam reprimendas dos adultos presentes nas cenas).

Apesar do formato romance, a rápida sucessão de eventos e a divisão em capítulos curtos visam claramente à serialização, com vários capítulos podendo ser considerados yarns mais ou menos independentes. O capítulo 3, por exemplo, é dedicado ao bem-sucedido plano de Jack e Harry para conseguir o dinheiro necessário para as passagens de trem de sua fuga, apostando no cavalo azarão da Melbourne Cup (famoso evento esportivo anual que mobiliza toda a Austrália); no capítulo 12 os rapazes, tendo feito amizade com Reynold, menino aborígene, conhecem outros membros da comunidade à qual Reynold pertence, sendo aceitos como aprendizes em uma comitiva de drovers, tropeiros que conduzem boiadas pelo interior da Austrália, chefiada por Uncle Warri, tio de Reynold. Uncle Warri é drover experiente e acaba se tornando mentor dos meninos, ensinando-lhes tanto o ofício do tropeirismo quanto bushcraft, ou a arte de sobrevivência no outback australiano. Uncle Warri, seguindo os preceitos tradicionais das culturas indígenas australianas, ensina Jack a caçar, respeitando, porém, a prática aborígine de capturar somente o alimento necessário para a subsistência, em contraposição à caça esportiva europeia. No capítulo 26, tendo chegado a Coober Pedy, Jack, Harry e Reynold, em clima de western, expulsam três bandidos que tentam roubar a mina de opala que estão escavando. Esses episódios são entremeados por cenas urbanas, centradas na aflição das famílias, suas ações para tentar encontrar os filhos e o processo de investigação policial que a certa altura os inocenta, permitindo um desfecho feliz com o retorno - glorioso, ainda que temporário - dos rapazes, agora experientes, seguros e independentes financeiramente.

A versão do texto para áudio-livro (2005) é particularmente feliz na escolha do ator australiano David Tredinnick para a leitura do romance. Ao recriar uma versão em áudio da obra, Tredinnick habilmente utiliza diferentes modalidades e inflexões de voz para dar identidade ao narrador e aos diversos personagens, masculinos e femininos, um 


\section{Revista Leteas Racar}

ISSN: 2317-2347 - v. 7, Edição Especial (2018).

desafio considerável, já que envolve a criação de mais de 30 "personas” linguísticas. Isso aproxima o romance ainda mais do yarn tradicional, obviamente, numa escala ampliada. Outra estratégia de Tredinnick para compor as personas linguísticas é a utilização de diferentes socioletos. Como explicam Mesthrie et. al. (2009, p. 131), existem basicamente três categorias sociolinguísticas de inglês australiano: cultivated, variante culta, a mais próxima do inglês britânico padrão, falada por uma minoria da população, general, variante "geral" utilizada pela maioria dos australianos e broad, a variante mais distanciada da variante culta, especialmente quanto à pronúncia das vogais, encontrada em toda a extensão do território, mas associada particularmente a certos grupos, por exemplo, populações periféricas ou rurais. Tredinnick utiliza a variante general para o narrador e personagens de status sócio-econômico mais elevado e broad para as falas da maioria dos personagens. ${ }^{8}$ Faz também uso das subvariantes accented, que apresentam fortes sinais de "sotaque", ou transferência de uma língua estrangeira para o inglês australiano (MESTHRIE et al., p. 131), nas falas dos imigrantes arrendatários de minas em Coober Pedy Ishmo (afegão) e Bruno (italiano), além de procurar reproduzir o sotaque irlandês do bon vivant Paddy e dos padres católicos Father O’Malley e Sean Logan, que também se tornam figuras de referência para os meninos. Ao criar diferentes ritmos, humores, emoções e energias para os personagens e episódios, Tredinnick se aproxima da figura do contador de histórias popular/yarn spinner tradicional.

Quanto à verossimilhança, yarns, causos e tall tales utilizam estratégias semelhantes. Analisando o tall tale, Carolyn Brown (1989, p. 93) observa como esta modalidade de conto costuma apresentar, em seu ponto de partida, eventos comuns e pessoas comuns, mas que a certa altura acabam se encaminhando para o grotesco ou o insólito, caracterizando-se "uma ficção cômica disfarçada como fato, deliberadamente esticada até os limites da credibilidade ou além para revelar verdades emocionais, despertar o público, exorcizar medos, definir e unir um grupo social” (BROWN, 1989, p. 2). ${ }^{9}$ Quanto aos causos brasileiros, Costa (2008, p. 68) percebe que estes podem ser inspirados por fatos banais do dia-a-dia ou por eventos surpreendentes ou mesmo

\footnotetext{
${ }^{8}$ Meus agradecimentos ao Prof. Dr. Ian Alexander, pelo auxílio na análise das falas.

9 " a comic fiction disguised as fact, deliberately exaggerated to the limits of credibility or beyond in order to reveal emotional truths, to awaken his audience, to exorcise fears, to define and bind a social group."
} 


\section{Revista Leteas Racar}

ISSN: 2317-2347 - v. 7, Edição Especial (2018).

imaginários. Até quando tratam de acontecimentos fantásticos (tais como as "assombrações" do folclore brasileiro), os causos diferem de outros gêneros populares por apresentarem tempo e espaço da narrativa razoavelmente bem localizáveis, contrapondo-se, por exemplo, à indefinição do "era uma vez num reino distante" de seus "primos", os contos de fadas. Também Brown (1989, p. 93) ressalta a estratégia adotada pelo tall tale de fazer uso de um cenário geograficamente localizável para atribuir verossimilhança às narrativas.

Há, de fato, uma grande preocupação com o tempo e o espaço da narrativa em Jack and Harry. Os seis meses de tempo ficcional seguem uma espécie de roteiro de viagem ${ }^{10}$ que pode ser facilmente traçado pelo leitor/ouvinte no mapa da Austrália, já que há constantes alusões a cidades, vilarejos, acidentes geográficos e a outros pontos de referência e topônimos em geral. A introdução da versão impressa do livro traz esse mapa, explicitando todos os locais por onde Jack e Harry passam. Também várias características físicas e acontecimentos históricos e culturais ocorridos nesses locais são mencionados. Por exemplo, o cavalo vencedor da Melbourn Cup em 1950 chamava-se Comic Court, coincidindo com o "palpite" do pai de Jack (aposta que rende aos meninos os fundos necessários para sua fuga); Anna Creek Station, onde os meninos passam o Natal juntamente com a comitiva de tropeiros, é, até hoje, a maior fazenda de gado no mundo, com $23.000 \mathrm{~km}^{2}$ de área; outro dado histórico mencionado é o de que em 1945 houve um rápido impulso na atividade mineradora em Coober Pedy graças à descoberta de um veio de opala bem próximo à superfície por Toddy Bryant, uma mulher aborígine local. Ficamos sabendo que amenizar as altas temperaturas do clima desértico é a razão por detrás das bizarras habitações subterrâneas de Coober Pedy, e assim por diante.

Fica claro que as aventuras de Harry e Jack têm como modelo uma das principais vertentes do yarn, a vertente rural, conhecida como bush yarn. Esse tipo de narrativa popular entrou em evidência na segunda metade do século XIX, com a intensificação da exploração pecuária das áreas interioranas mais próximas à costa conhecidas como the bush. As grandes fazendas de gado e ovinos, conhecidas como stations, empregavam trabalhadores sazonais e itinerantes que disseminavam seus

\footnotetext{
${ }^{10}$ Como curiosidade, em tempos de mídias sociais a obra já tem até mesmo alguns fãs, que mencionam os personagens em seus blogs de viagem. Ver, por exemplo, "Following Jack and Harry". http://cuttingalap.blogspot.com/2015/12/following-jack-and-harry.html. Acesso em 26/08/2018.
} 


\section{Reuista Leteas Racas}

ISSN: 2317-2347 - v. 7, Edição Especial (2018).

yarns, poemas e baladas em rodas de fogueira, acampamentos e galpões. Segundo o historiador Russel Ward na influente obra The Australian legend, publicada originalmente em 1958, o estilo de vida desses tropeiros, peões, vaqueiros, tosquiadores e outros trabalhadores rurais, bem como as narrativas por eles criadas e disseminadas, acabaram influenciando a imagem que os australianos construiriam de si mesmos, mesmo após a modernização da Austrália, dando ênfase desproporcional ao estilo de vida rural (considerando que a sociedade australiana foi predominantemente urbana ao longo de toda sua história). A mitificação do estilo de vida rural remete à crença na capacidade de adaptação especial dos bushmen à vida dura do interior australiano. Nascia, assim, um orgulho nacionalista baseado nas grandes distâncias, na solidão e na aridez, desafios constantes à sobrevivência humana, não presentes nos ambientes rurais da Inglaterra, já há muito domesticados.

Em sua transposição do bush yarn para o romance de aventura juvenil, McKenna e Davis recorrem frequentemente aos princípios da tradição rural descrita por Ward. O título do romance já faz referência indireta a dois atributos do "australiano típico" (WARD, 1992, p. 180): o pendor para o igualitarismo e a cultura do mateship. "Jack" e "Harry" estão dentre os nomes próprios masculinos mais populares na língua inglesa. "Jack", particularmente, costuma aparecer em expressões idiomáticas que denotam um sujeito comum, marinheiro, empregado ou faz-tudo (SPEAKE, 2015, p. 165). A expressão Jack is as good as his master sugere igualdade entre Jack e seu mestre/patrão, ou seja, um status social superior não implica em superioridade de caráter (MANSER, 2007, p. 156). Essa mesma expressão é adotada por Ward (1992, p. 180): o australiano típico “acredita que Jack não só e tão bom como seu mestre, mas, pelo menos em princípio, provavelmente o supera", ${ }^{11}$ novamente uma contraposição à sociedade inglesa, conhecida por sua divisão de classes inflexível e valorização da aristocracia. Além disso, o australiano seria "descrente de pessoas eminentes, a menos que, como no caso de seus heróis esportivos, eles demonstrem ter habilidades físicas especiais"12 (WARD, 1992, p. 180). Jack e Harry, ao percorrerem o interior australiano, adquirem

\footnotetext{
11 "believes that Jack is not only as good as his master, but, at least in principle, probably a good deal better."

12 "knocker of eminent people, unless, as in the case of his Sporting heroes, they are distinguished by physical prowess."
} 


\section{Revista Leteas Racar}

ISSN: 2317-2347 - v. 7, Edição Especial (2018).

tais habilidades físicas valorizadas pelo mito australiano: montar, acampar, aboiar, rastrear animais, caçar, cavar minas...

Uma outra metáfora de grande recorrência nas variantes australianas do inglês é tall poppy - uma papoula que se sobressai às outras em termos de altura - ou seja, alguém que utiliza sua posição social e financeira superior de forma arrogante, merecendo o descrédito e a antipatia das demais "papoulas" (MOORE, 2008, p. 149). Mr. Munse, o vilão do romance, é caracterizado como um típico tall poppy australiano, o que fica evidente em sua justificativa quanto à proibição do empréstimo da bicicleta: "Eles são um bando de proletários e não profissionais como nós" (MCKENNA; DAVIS, 2005a, p. 9). ${ }^{13}$ Da mesma forma, quando questionado pela esposa, Mr. Munse assim explica ter matriculado Billy em uma escola pública, mesmo tendo recursos para fazê-lo numa particular:

William tem que aprender a se misturar com as pessoas comuns da vida, mas sem se juntar a elas. Desse modo ele vai aprender como elas são e o que as motiva. Assim, quando ele eventualmente se formar advogado e vier trabalhar na firma comigo, ele compreenderá melhor sua mentalidade. Afinal de contas, essas são as pessoas que normalmente se complicam com a justiça e precisam de um advogado para defendê-las ${ }^{14}$ (MCKENNA; DAVIS, 2005a, p. 10).

Estabelece-se, assim, uma contraposição entre classes sociais, comum nos yarns. ${ }^{15}$ Em Jack and Harry essa oposição vai se acirrar pela acusação de roubo, um ponto considerado tabu na sociedade australiana da primeira metade do século XX, ainda assombrada pela memória de suas origens "escusas" como colônia penal.

Porém, a acusação injusta também desencadeia um plano de fuga ao mesmo tempo ingênuo e audacioso, nos moldes dos grandes livros de aventura juvenis do cânone de língua inglesa, tais como Tom Sawyer e Oliver Twist. O intuito de tais narrativas de aventura é a criação de um mundo ficcional que John Cawelti coloca nos seguintes termos:

\footnotetext{
13 "They are just a blue collar mob, not professional people, like us."

14 "William has got to learn how to mix with the ordinary people of this world, but not to be part of them. That way, he'll learn what they are like, what makes them tick. So that when he eventually graduates from the bar and comes to the firm with me he'll understand their mentality more. After all, they're the ones who are usually in trouble with the law and need a solicitor to defend them."

${ }^{15}$ Existem também os yarns literários da literatura australiana, publicados em revistas e livros, cujo autor mais lembrado é Henry Lawson e que se tornaram paradigmáticos da literatura australiana a partir da década de 1890.
} 


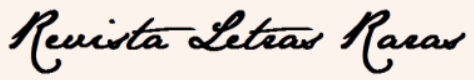

ISSN: 2317-2347 - v. 7, Edição Especial (2018).

um mundo imaginário ligeiramente distanciado da nossa realidade ordinária, mas somente o suficiente para que nos sintamos um pouco menos inclinado a colocar em prática nossos padrões usuais de verossimilhança e probabilidade. Ao imergirmos nesse mundo fica mais fácil conseguir escaparmos de nós mesmos para dentro dos protagonistas e suas histórias ${ }^{16}$ (CAWELTI, 1976, p. 19).

Esse é o apelo da fórmula da história de aventura - e, no caso de Jack and Harry, da sequência de yarns que seguem a fórmula de aventura. McKenna e Davis adotam esse tipo de fórmula ao adicionar, a cada capítulo/episódio, um certo grau de suspense. Cawelti descreve isso como

a habilidade do autor em evocar em nós um sentimento de medo e incerteza temporário sobre o destino de um personagem com o qual nos preocupamos. É um tipo especial de incerteza que aponta sempre para uma possível resolução ${ }^{17}$ (CAWELTI, 1976, p. 17).

Desse modo, capítulo após capítulo, as pequenas crises vão surgindo e sendo rapidamente solucionadas. No capítulo 3, como não têm idade para entrar no pub onde estão sendo feitas as apostas para a Melbourne Cup, entregam o pouco dinheiro que conseguiram juntar a um sujeito desconhecido, com recomendações para que realize a aposta. Pouco depois, acompanhamos com ansiedade enquanto eles esperam que outro simpático, porém suspeito desconhecido recolha o prêmio - o que acaba acontecendo sem demais dificuldades. Esse suspense também ocorre no capítulo 6, na cidadezinha de Kalgoorlie, quando colocam quase todo o lucro das apostas nas mãos de um outro bon vivant, Paddy O'Brien, que promete apostar a quantia no jogo de azar de two-up. Novamente saem-se muito bem, tendo um excelente retorno para o "investimento". Se essa fórmula talvez pareça um tanto inverossímil para os parâmetros do romance mimético, ao entendermos a narrativa como uma série de yarns de aventura ela "preenche as necessidades humana de prazer e fuga", papel que vem sendo cumprido pelos arquétipos literários há milênios, segundo Cawelti (1976, p. 6).

\footnotetext{
16 "an imaginary world that is just sufficiently far from our ordinary reality to make us less inclined to apply our ordinary standards of plausibility and probability to it. If we become immersed in such a world, it is easier for us to escape from ourselves into identification with a story's protagonists."

17 "the writer's ability to evoke in us a temporary sense of fear and uncertainty about the fate of a character we care about. It is a special kind of uncertainty that is always pointed toward a possible resolution."
} 


\section{Revista Leteas Racar}

ISSN: 2317-2347 - v. 7, Edição Especial (2018).

De desafio em desafio, durante os quais precisam provar sua força de caráter (apesar das pequenas transgressões, especialmente mentiras que contam para esconder a verdadeira identidade) e habilidades físicas necessárias para enfrentar a vida no outback, a dupla vai se aproximando do Coober Pedy, onde pretende "desaparecer do mapa" e, quiçá, fazer fortuna. Contrastando com os títulos citados acima - Tom Sawyer e Oliver Twist - o fato de que Jack e Harry formam uma dupla, mas, mais especificamente, são mates, é outro elemento crucial no contexto da tradição rural australiana e do yarn. Mate é mais um australianismo de difícil tradução. De acordo com The Australian national Dictionary (apud MOORE, 2008, p.104) mateship remete a uma "ligação entre parceiros em situação de igualdade ou amigos próximos, [...] camaradagem como um ideal". ${ }^{18}$ Jack e Harry - que tomam todas as decisões em conjunto e finalmente, voltam para casa dividindo os benefícios financeiros em partes iguais - são basicamente os protótipos dos mates como Ward (1966, p. 4) os define, sujeitos que permanecem leais um ao outro qualquer que seja a situação. Até mesmo na disponibilidade em partilhar todas as experiências eles seguem o modelo de Ward, já que um mate seria um indivíduo com quem se pode repartir "dinheiro, objetos e até mesmo aspirações secretas e pelo qual, mesmo quando errado, ele estava preparado a fazer praticamente qualquer sacrifício" (WARD, 1966, p. 99). ${ }^{19}$

Como se pode constatar, as agruras do espaço rural australiano são cruciais para o estabelecimento do mateship. É sabido que devido à cultura trabalhista itinerante, duplas ou pequenos grupos de homens - a pé ou a cavalo - eram uma ocorrência comum nas regiões rurais da Austrália. Andar desacompanhado constituía uma grande imprudência, já que diversas variáveis podiam pôr em risco o bem-estar físico e emocional do viajante, bem como sua vida. Em Jack and Harry, Harry comete essa inadvertência no capítulo 16, quando sai do acampamento dos drovers sozinho em busca de água. Após uma serpente assustar seu cavalo, ele se perde no deserto e é encontrado, já desfalecido, graças à grande sabedoria de Uncle Warri, que percebe um grupo de aves de rapina sobrevoando a iminente presa.

Esse e outros episódios de valorização dos personagens aborígenes presentes em boa parte dos capítulos, evidencia uma das ocasiões em que McKenna e Davis se

\footnotetext{
18 "the bond between equal partners or close friends; comradeship; comradeship as an ideal".

19 "money, goods, and even secret aspirations and for whom even when in the wrong, he was prepared to make almost any sacrifice"
} 


\section{Revista Leteas Racar}

ISSN: 2317-2347 - v. 7, Edição Especial (2018).

afastam momentaneamente da tradição rural, numa tentativa de atualizar o yarn, ou deixá-lo mais aceitável e politicamente correto para o público-alvo juvenil contemporâneo. Isso se faz necessário porque, por detrás da igualitarismo apregoado pela cultura rural australiana descrita por Ward, ocultava-se a rejeição às minorias: "nenhum negro, nenhum chinês, nenhum indiano, nenhum melanésio, nenhum indivíduo de cor fornecedor de trabalho barato, é australiano" (apud LEE, 2004, p. $21)^{20}$, afirmava um famoso editorial do periódico Bulletin, por muitas décadas o mais popular veículo propagador da literatura popular australiana e que, de 1908 a 1960 chegou a exibir o lema "A Austrália para o homem branco" 21 em sua primeira página. Mulheres, povos indígenas e minorias étnicas normalmente não figuravam como personagens dos yarns, das baladas e mesmo dos contos literários ou se apareciam eram retratados de forma pejorativa.

Na obra de McKenna e Davis, no entanto, além dos personagens aborígines Uncle Warri, Reynold, Nigel e Wandoo, a Austrália multicultural, também ignorada ou menosprezada pela tradição rural, aparece representada pelos personagens de Ishmo, um condutor de camelos afegão e de Bruno, um minerador de opalas italiano a quem Jack e Harry se afeiçoam e que acabam contribuindo ativamente para as aventuras e para o processo de amadurecimento pessoal e financeiro dos meninos. Entretanto, há ainda um outro aspecto excludente do mateship. Como lembra Elaine Thompson (1994, p. 132133): "Os mates desenvolviam relações de dependência emocional, até mesmo como forma de manter a sanidade. Essa dependência tornava-se uma forma de ligação masculina que frequentemente se mostrava ambivalente em relação às mulheres como companheiras, se não abertamente hostis a elas."22 Para contrapor-se a essa exclusão, McKenna e Davis incluem (porém já nos últimos capítulos do romance, quando Jack e Harry estão a caminho de casa) um encontro entre Jack e Naomi Wilson, uma adolescente empoderada e questionadora, proporcionando uma breve incursão na temática da igualdade de gêneros que será melhor desenvolvida na sequência da duologia, Jack and Harry: Beyond tomorrow.

\footnotetext{
20 "no nigger, no Chinaman, no lascar, no kanaka, no purveyor of cheap coloured labour, is an Australian"

21 "Australia for the white man"

22 "Mates developed relationships of emotional dependence, a prop at times even for their sanity. That dependence became a form of male bonding which often displayed an ambivalence towards women as companions, if not direct hostility to them."
} 


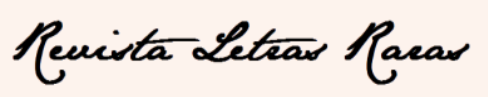

ISSN: 2317-2347 - v. 7, Edição Especial (2018).

\section{Considerações finais}

Jack and Harry: No turning back constitui-se uma narrativa prazerosa, tanto para adolescentes e jovens, seu público-alvo básico (tendo em vista a caracterização dos protagonistas), quanto para leitores mais maduros. Ao unirem as fórmulas da história de aventura e do bildungsroman, McKenna e Davis evocam uma das funções primevas da literatura popular/contação de histórias - a possibilidade de vivermos, vicariamente, situações de tensão e perigo que margeiam o inverossímil, mas que, já sabemos de antemão, levarão à fortuna e ao crescimento pessoal. Em termos de temática, trazem para o romance alguns dos elementos culturais e ideológicos que os australianos têm constituído no decorrer de sua história, tais como o igualitarismo e o mateship e a identificação com a cultura rural. Também ao estruturarem a narrativa em capítulos curtos (muitos deles, como vimos, historietas independentes) e explorarem o vernáculo australiano - o que se destaca na versão em áudio do romance - os autores aproximam a modalidade literária do romance ao gênero textual yarn. E apesar de não terem grandes preocupações com o fator politicamente correto (lembremos, afinal, que o enredo se passa na década de 1950), os autores procuram esquivar-se das características mais patentemente excludentes das narrativas populares da tradição rural australiana, ao buscar um clima de empatia entre os protagonistas e as minorias raciais e étnicas de sua sociedade.

\section{REFERÊNCIAS}

BROWN, C. The tall tale in American folklore and literature. Knoxvile: The University of Tenessee Press, 1989.

CAWELTI, J. Adventure, mystery and romance: Formula stories as art and popular culture. Chicago: The University of Chicago Press, 1976.

COSTA, S. Dicionário de gêneros textuais. Belo Horizonte: Autêntica, 2008.

DAVEY, G.; SEAL, G. A guide to Australian folklore: From Ned Kelly to Aeroplane Jelly. Sydney: Kangaroo Press, 2003.

GILGE, P. To swear like a sailor: Maritime culture in America, 1750-1850. New York: Cambridge University Press, 2016. 


\section{Revista Leteas Racar}

ISSN: 2317-2347 - v. 7, Edição Especial (2018).

HAYNES, J. The best Australian yarns and other true stories. Sydney: Allen \& Unwin, 2013.

LEE, C. City bushman: Henry Lawson and the Australian imagination. Fremantle: Curtin, 2004.

MANSER, M. The facts on file dictionary of proverbs. New York: Facts on File, 2007.

MCKENNA, T., Jack and Harry II: Beyond Tomorrow. Narrado por David Tredinnick. Sydney: ABC Audio, 2015. Audiolivro.

MCKENNA, T.; DAVIS, M. Jack and Harry: No turning back. Narrado por David Tredinnick. Melbourne: Bolinda Audio, 2005. Audiolivro. Pty, 2005a.

Jack and Harry: No turning back. Perth: Australian Arts and Entertainment

MESTHRIE, R. et al. Introducing sociolinguistics. Edinburgh: Edinburgh University Press, 2009.

MOORE, B. Speaking our language: the story of Australian English. Oxford: Oxford University Press, 2008.

SCHEIDT, D. Um olhar além: o sertão brasileiro e o outback australiano comparados. Revista de História Regional, v. 15, n. 2, 2010.

SEAL, G. The lingo: Listening to Australian English. Sydney: University of New South Wales Press, 1999.

SPEAKE, J. (ed.). Oxford dictionary of proverbs. Oxford: Oxford University Press, 2015.

THOMPSON, E. Fair enough: Egalitarianism in Australia. Sydney: University of New South Wales Press, 1994.

VAUX, J. Memoirs of James Hardy Vaux written by himself. Vol. I. London: W. Clowes, 1819.

WARD, R. The Australian Legend. Melbourne: Oxford University Press, 1966.

Data de recebimento: 30/09/2018

Data de aceite: 25/11/2018 